\title{
Kurt Jellinger, Doyen of international neuropathology
}

\author{
Gregor K. Wenning ${ }^{1} \cdot$ Peter Riederer ${ }^{2}$
}

Accepted: 27 July 2021 / Published online: 22 August 2021

(c) The Author(s), under exclusive licence to Springer-Verlag GmbH Austria, part of Springer Nature 2021

Kurt Jellinger was born in Vienna on May 28, 1931 and studied medicine at the Medical Faculty at the University Vienna, Austria. He finished his studies with a Dr. med. univ. "sub auspiciis praesidentis" in 1956 and soon specialized in clinical neurology and neuropathology becoming a private lecturer ("Privat-Dozent") in 1967. He became Head of the Department of Neuropathology and University Professor in 1973.

A hard worker with a brilliant feeling for current scientific topics, Kurt Jellinger became soon a well-known international scientist and received several offers for top positions in Germany and the United States. But instead of accepting these offers, he decided to apply for the position of Primarius (Director) of Neurology at Lainz-(Municipal) Hospital, a position which he held until his retirement in 1997. He succeeded Walther Birkmayer in 1976 not only in the directorship of the Department of Neurology but also as Director of the Ludwig-Boltzmann-Institut (LBI) of Neurochemistry, which he later renamed "LBI of Clinical Neurobiology".

One of us (PR) had the chance to work with both, Walther Birkmayer (1971-1975) and Kurt Jellinger (1976-1986) as Head of the laboratory for Neurochemistry. This was an extremely successful cooperation starting in 1974 with scientific projects in the fields of schizophrenia, brain infarction and metabolic encephalopathies, resulting in many scientific papers.

Gregor K. Wenning

Gregor.Wenning@i-med.ac.at

Peter Riederer

peter.riederer@mail.uni-wuerzburg.de

1 Division of Clinical Neurobiology, Dysautonomia Center, Medical University, Anichstrasse 35, 6020 Innsbruck, Austria

2 Clinic and Policlinic for Psychiatry, Psychosomatics and Psychotherapy, University Hospital Wuerzburg, Margarete Hoeppel-Platz 1, 97080 Wuerzburg, Germany

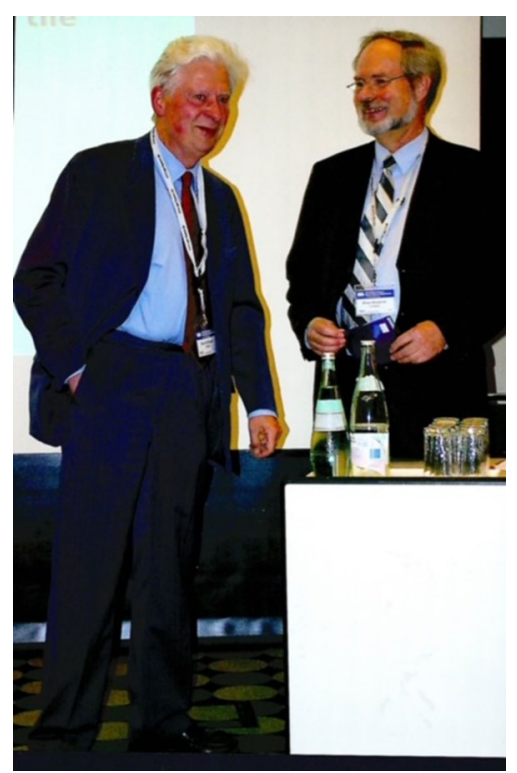

To make appointments with Kurt to discuss arising scientific issues or administrative problems was never an easy task, but Kurt responded always quickly and his information was short-cut, precise and frequently given at unforeseen meetings in the corridor. And he always supported our ideas and research activities in the Neurochemistry-Neurobiological laboratory. This was also the case in my (PR) proposal in 1975 to continue research on iron-induced pathological processes which became an important topic in the field of Parkinson's disease and Alzheimer's disease and contributed to the understanding oxidative stress and the action of reactive oxygen species in these disorders. And Kurt Jellinger focused to explore the etiopathogenesis of Parkinson`s disease and Alzheimer disease. It was a decade of ideal interaction of neuropathology and neurochemistry and thus the basis for the idea to establish a human post-mortem brain bank in Würzburg, Germany, after PR moved to the Clinic and Policlinic for Psychiatry, Psychosomatics and Psychotherapy, University Hospital Würzburg, Germany, to 
establish a laboratory for Clinical Neurochemistry. It was the beginning of the Austria-German brain bank.

Kurt Jellinger has always been and still is an expert neuropathologist, world-wide known to translate the most recent literature and conference knowledge into neuropathological analyses. His archives on literature and human post-mortem brain tissue have been and still are the backbone of his success. Together with W. Paulus, C. Bancher and J. Attems, he made substantial contributions towards the understanding of pathological processes of neurodegenerative disorders. With the combination of neuropathological methodology and the neurochemical armamentarium of analytical methods, Kurt Jellinger pioneered the field as shown with the collaboration of Oleh Hornykiewicz, Hanno Bernheimer and one of us (PR).

Kurt Jellinger became highly influential in research on multiple system atrophy (MSA) generating the first neuropathological grading scheme of this complex disorder in 2005 together with one of the editors (GKW). His interactions with him started in 1993 and have continued until now, almost 30 years. Kurt Jellinger was not only interested in delineating classical neuropathological changes in MSA but also in understanding its molecular biological underpinnings.

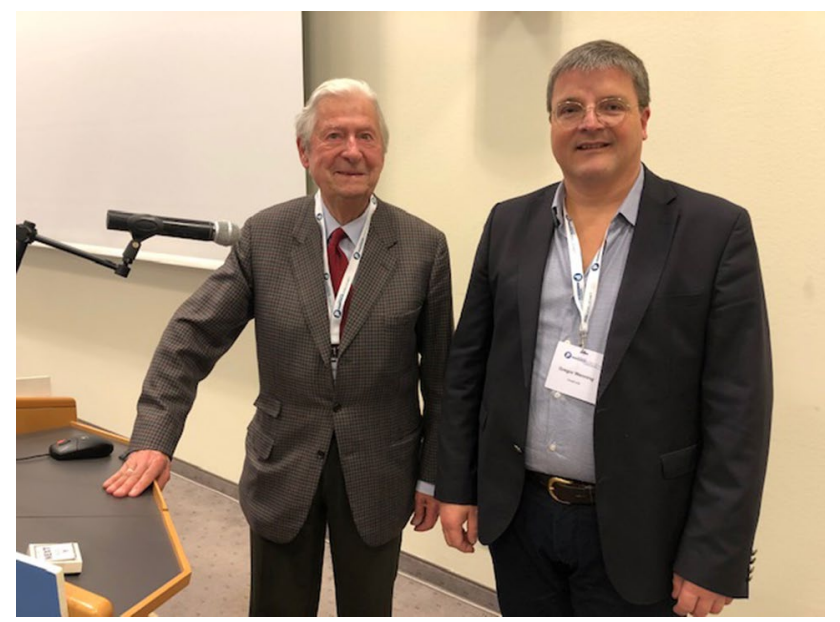

Kurt Jellinger received many honours and awards. He was president of the Austrian Society of Neurology and Psychiatry (1990-1992), President of the Austrian Society of Neuropathology (1994-1998) and he still joins the board of the Austrian Alzheimer Society, where he was Vice-President (1997-2002) and elected as an Honorary Member. He was Vice President of the International Society of Neuropathology from 1981 to 1984 and he co-organized the 1. European Congress of Neuropathology, Vienna, 1980, as well as the 9. International Congress of Neuropathology, Vienna, 1982.

He was Chairman of the EU neuropathology working group from 1996 to 1999, and secretary of the European Society of Psychopharmacology (1994-2000).
Kurt became an honorary member of several national and international societies, including the American, British, German, Hungarian and Austrian Societies of Neuropathology, the German Societies of Neurology and Pathology, the Austrian Neuroscience Association, the Austrian and German Parkinson Societies and other honours, like the Alzheimer Obelisk in 1998; the Lundbeck Award for Parkinson Research, 2003 and the Senator-Doctor Franz Burda Award, 2000, the Karl Maria Jakob Medal of the German Association of Neuropathology, 2003, the Istvan Környey Tarscosag award, 2005, the Cotzias Award of the Movement study group of the Spanisch Society of Neuropathology, 2011. Kurt Jellinger was Editor-in-Chief of Acta Neuropathologica from 1976 until 2004 and served at the editorial boards of several scientific journals, including Journal of Neural Transmission, in which he published many excellent articles and key reviews in Neuropathology of neurodegenerative disorders.

Even after his retirement as Head of the Department of Neurology, Lainz-Hospital in 1997 and of the LBI in 2002, Kurt continued in his scientific endeavours and it seems, that without the burden of any administration, he became engaged with even more empathy in his beloved neuropathological science.

More than 1000 publications can be listed. Of notion, his h-factor increased from 2011, when he celebrated his 80th birthday from 71 to nowadays more than 100, demonstrating his engagement and enthusiasm for neuropathology even in the time of his retirement. And he was very active to hold lectures at congresses and meetings until his age of 89 years-altogether more than 1300 !

Dear Kurt, it was and still is a privilege, honour and great pleasure to work with you and to get insights with you into the heterogeneity of many neuropsychiatric disorders and in particular into PD and AD.

Enjoy life with your beloved wife Lisl in Vienna and your domicile at the Hohe Wand, lower Austria. Lean back in a comfortable chair and see and read what your scholars and international scientific friends publish, which directions in science they go and prefer and how they translate basic science into clinical practise.

You and your science were and still are the basis of nowadays molecular biological and-genetic studies to unravel the mysteries of neurodegenerative disorders.

Ad multos annos!

Publisher's Note Springer Nature remains neutral with regard to jurisdictional claims in published maps and institutional affiliations. 